\title{
Removal of Seeds of Exotic Jackfruit Trees (Artocarpus Heterophyllus, Moraceae) in Native Forest Areas with Predominance of Jackfruit Trees in the Duas Bocas Biological Reserve, Southeastern Brazil
}

\author{
Mile na Mile ri ${ }^{1, *}$, Marcelo Pass amani ${ }^{2}$, Fre de rico Eutrópio $^{3}$, Aliny Olive ira ${ }^{1}$ \\ ${ }^{1}$ Laboratório de Ecologia e Conservação da Biodiv ersidade - LECB, Mestrado em Ecologia de Ecossistemas, Universidade Vila Velha, Rua \\ Comissário José Dantas de Melo, 21, Boa Vista, 29102-770, Vila Velha, Espírito Santo, Brazil \\ ${ }^{2}$ Laboratório de Ecologia e Conservação de Mamíferos, Setor de Ecologia, Departamento de Biologia, Universidade Federal de Lavras, \\ 37200-000, Lavras, Minas Gerias, Brazil \\ ${ }^{3}$ Laboratório de Microbiologia Ambiental e Biotecnologia - LM AB, Doutorado em Ecologia de Ecossistemas, Universidade Vila Velha, \\ Rua Comissário José Dantas de Melo, 21, Boa Vista, 29102-770, Vila Velha, Espírito Santo, Brazil
}

\begin{abstract}
This study examined the removal of seeds of the exotic jackfruit Artocarpus heterophyllus (Lamarck) by mammals in a native forest area with predominance of jackfruit trees in the Duas Bocas Biological Reserve, Southeastem Brazil. The seed removal experiments were made in an area with the predominance of jackfru it trees and in an native forest between January and October 2010. At each sampling area three distinct treatments (control: seeds that can be accessed by any species of mammals; semi-protected: seeds that can be accessed only by species of small mammals; and protected: seeds that can not be accessed by any species of mammals) were displayed containing seeds of A. heterophyllus. The area predominated by jackfru it trees showed a greater removal of seeds (35.6\%) co mpared to the native forest $(21.6 \%)$. The results showed that there was no significant difference in the amount of seeds removed from each area in the protected and control treatments. However, there was a higher seed removal in the semi-protected treatment in jackfruit trees area. In the native forest the removal was significantly higher in the control than in the other treatments. In the jackfruit trees area, the removal of seeds in the control was significantly higher than in the protected treatment. Of the species recorded by camera traps, Trinomys paratus can be considered the main disperser in the jackfruit area, contributing to the dispersal of $A$. heterophyllus, an invasive plant species. Thus, a management plan for A. heterophyllus at the Duas Bocas Biological Reserve should be carried out partially, gradually and slowly, so that the populations of vertebrate species that now depend on this resource for food do not suffer a drastic impact.
\end{abstract}

Keywords Invasion Species, Jackfruit, Seed Remove, Mammals Dispersion, Atlantic Forest

\section{Introduction}

Species of small mammals have an important role in the environments through predation and seed dispersal that together are major determining factors in the recruitment of new plants $[1,2]$. The dispersal of individuals can be influenced by variation in the abundance and distribution of food resources[3] which, in turn, are influenced by the seasonality of the climate[4]. It is estimated that in tropical forests from $50 \%$ to $90 \%$ of all trees are dispersed by animals (zoochory), while about $20 \%$ to $50 \%$ of bird and mammal species consume fru its during, at least, part of the year[5].

* Corresponding author:

milenamilleri@yahoo.com.br (Milena Mileri)

Published online at http://journal.sapub.org/ije

Copyright (C) 2012 Scientific \& Academic Publishing. All Rights Reserved
Some authors cite rodents as essential predators and dispersers of medium and large seeds of trees[6-9]. Currently, the role played by small rodent communities as seed predators remains neglected, with few studies, since the abundance of these individuals and their dispersal are affected by a myriad of factors such as seed size[10], availability and location of fruits[11], availability of nests[12], habitat characteristics[13, 8], time of year[6], abundance of rodent predators[14], habitat size and hunting pressure[9].

Artocarpus heterophyllus Lamarck is a species native to the tropical forests of India, growing between altitudes of 450-1200 m. In Brazil, a well-developed jackfruit tree produces up to 100 fruits that may weigh up to more than 30 $\mathrm{kg}$, fructify ing especially in summer (December-February), with the main consumers being man and other mammals like rodents and primates[15]. One of the ecological effects 
caused by populations of this exotic species is that they grow in dense concentrations, excluding other species and thus altering the local biodiversity[16]. Moreover, this species is considered by many conservation unit managers as an invasive species in the region of the Atlantic Rainforest, causing them to control its population by using girdling techniques and other exclusion methods[17]. According to reference[16] many species native to the Atlantic Rain forest are probably being excluded because of the invasion by the species A. heterophyllus.

Thus, the aim of this study was to evaluate the role of mammals to removal and seed dispersal of an exotic species Artocarpus heterophyllus, both in native forest areas and in areas dominated by the jackfru it in Duas Bocas Biological Reserve, southeastern Brazil.

\section{Materials and Methods}

\section{Study Area}

The study was made in Duas Bocas Biological Reserve (REBIO), an area of Atlantic Rainforest[18] located in the state of Espírito Santo, southeastern Brazil (20 18'05”S $40^{\circ} 28^{\prime \prime} 06^{\prime \prime}$; F Figure 1). It has an area of 2.910 ha with altitudes ranging between 200 and $738 \mathrm{~m}$, and the climate is Tropical wet and dry AW[19]. The area consists mostly of forests in good state of conservation, but there are areas of secondary vegetation that is quite disturbed and in an advanced stage of regeneration. There is also an extensive area inhabited by adult individuals of the exotic species of jackfruit (Artocarpus heterophyllus) in intense reproductive activity and displaying the dynamics of a regenerating population. This area dominated by $A$. heterophyllus occupies a total of 19.6 ha wh ich represents $0.7 \%$ of the total area of the REBIO[20].

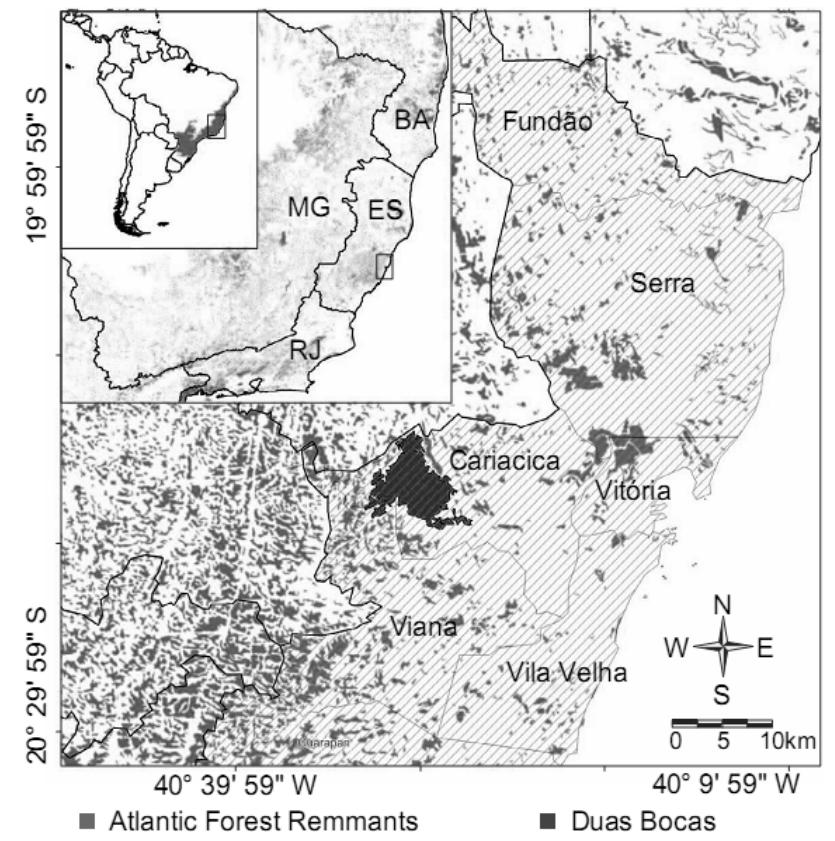

Figure 1. Map of the state of Espírito Santo, Brazil, showing the Duas Bocas Biological Reserve
Removal of seeds experiment: Comparison between two areas (native forest and area with predominance of jackfru it trees)

The seed removal experiment was prepared using seeds of the jackfruit $A$. heterophyllus. This species was chosen to assess how its seeds are dispersed by mammals in order to aid our understanding of the dispersal dynamics of exotic species when introduced into a native forest. Moreover, this is an abundant food resource in the REBIO throughout the year. The fresh seeds of $A$. heterophyllus when removed from the fruit measure approximately $30-40 \mathrm{~mm}$ in length and $10-20 \mathrm{~mm}$ in width. To prevent the seeds used in the experiments from germinating in areas of the REBIO, part of their germinative structure was removed before the treatments to make them unviable.

The first environment (area with the predominance of jackfruit trees) was characterized as the anthropic one $\left(20^{\circ}\right.$ $16^{\prime} 05^{\prime \prime} \mathrm{S}-40^{\circ} 29^{\prime} 02^{\prime \prime} \mathrm{W}$ ), consisting of intentional plantations of A.heterophyllus. The second environment (native forest) was located in an area of native forest $\left(20^{\circ} 16^{\prime} 48^{\prime \prime} \mathrm{S}-40^{\circ}\right.$ $280^{\prime \prime} \mathrm{W}$ ), located on the other side of the reservoir at a straight-line distance of about $1 \mathrm{~km}$ from the first environment.

To compare the removal of seeds between different sampled areas (area with the predominance of jackfruit trees and native forest), a 900-meter transect was set up in each area consisting of 10 points each, equidistant from one another by 100 meters. At each sampling point three distinct treatments (equidistant from one another by about $2 \mathrm{~m}$ ) were displayed containing five seeds of A. heterophyllus in each one ( 15 seeds per sample point). The treatments were control: seeds offered directly on the ground, so with unrestricted access by species of mammals; semi-protected: seeds placed inside a $40 \mathrm{~cm}$ piece of mediu $\mathrm{mVC}$ pipe ( $50 \mathrm{~mm}$ dia meter), allowing access only to species of small mammals; and protected: seeds placed inside a $40 \mathrm{~cm}$ piece of $\mathrm{s}$ mall $\mathrm{PVC}$ pipe (10 $\mathrm{mm}$ diameter), restricting the access of all species of mammals. The pipes were attached to the ground to prevent manipulation by animals.

The experiments were conducted in January, March, April, July, August and October 2010. The seeds of $A$. heterophyllus were arranged in all treatments every morning and checked after seven days of sampling. To assess the number of seeds removed, we took into consideration seeds that were completely removed from the treatments and seeds that remained intact within treatments in both environments studied.

In addition to using the treatments to evaluate seed removal by different size groups of mammals, we also used cameras with automatic shooting to identify which animals were removing seeds of $A$. heterophyllus. Throughout the experiment eight movement-activated Bushnell camera traps (model Spca 533), were set up, four in each study area. The points where the cameras were set up were randomly selected, targeted towards the control treatment or the semi-protected treatment, to identify the seed dispersers of $A$. heterophyllus. Camera traps were used during the seven 
consecutive days in each sampled period. An interval of 30 minutes between photographs was considered in such a way that several photographs taken consecutively were considered as one image, and a new photograph was counted 30 minutes after the first shot.

To calculate the number of seeds of $A$. heterophyllus removed by mammalian species, we counted the seeds that remained in the three treatments studied in each environment during of sampling. The treatments were tested for normality by the Kappa ${ }^{2}$ test[21]. To determine any significant differences between the native area and the area with the predominance of jackfruit trees, we used the Student $t$ test (P $<0.05)$. To test for significant differences between treatments within each area we used the ANOVA and Tukey test ( $p$ $<0.05)$.

\section{Results}

Of the 1800 seeds of $A$. heterophyllus used in the experiment, $514(28.6 \%)$ were completely removed. In the area with a predominance of jackfruit trees, $35.6 \%$ of seeds were removed and in the area of native forest, $21.6 \%$.

The comparison of each treatment between the two sampled areas showed that there was no significant difference in the amount of seeds removed fro m each area in the protected and control treatments $(\mathrm{t}=-1.236, \mathrm{p}=0.218$, and $\mathrm{t}=-1.820, \mathrm{p}=0.071$, respectively). However, there was a higher seed removal in the semi-protected treatment in the area with the predominance of jackfruit trees, compared with the area of native forest $(t=-3.233, p=0.001$, Figure 2$)$.

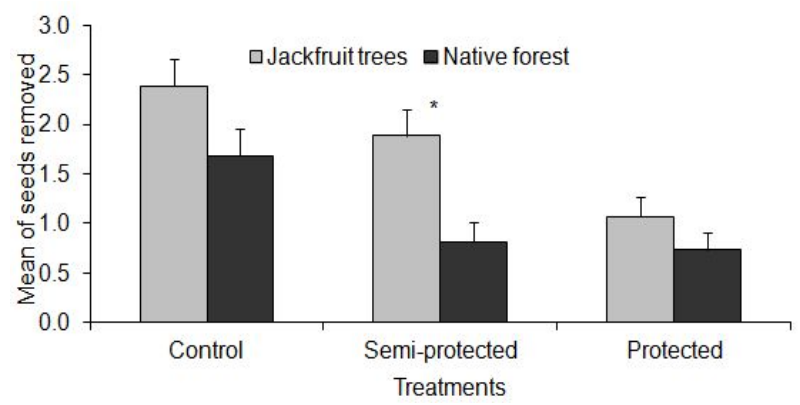

Figure 2. Mean of seeds removed among treatments in two areas studied. The bars indicate the means and standard deviation of seeds removed

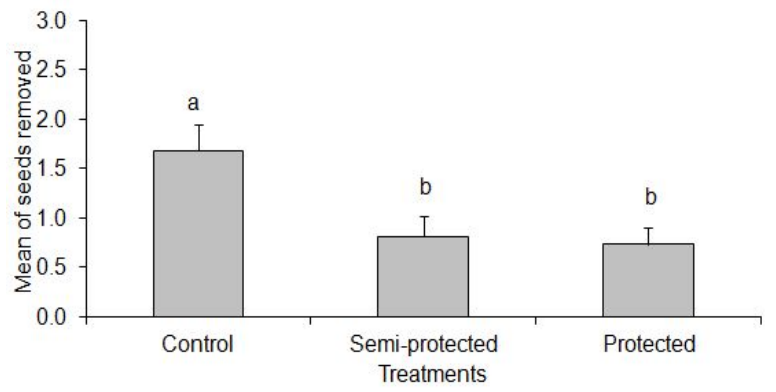

Figure 3. Mean of seeds removed among treatments in the native forest. The bars indicate the means and standard deviation of seeds removed. Different letters represent a significant difference

The removal of seeds in the area of native forest showed significantly difference $(F=5.812, p=0.003)$, with removal significantly higher in the control than in the other treatments (Figure 3).

In the area with a predominance of jackfruit trees, the removal of seeds in the control treatment was significantly higher $(\mathrm{F}=7.107, \mathrm{p}=0.001)$ than in the protected treatment. The semi-protected and protected treatments showed no significant difference (Figure 4).

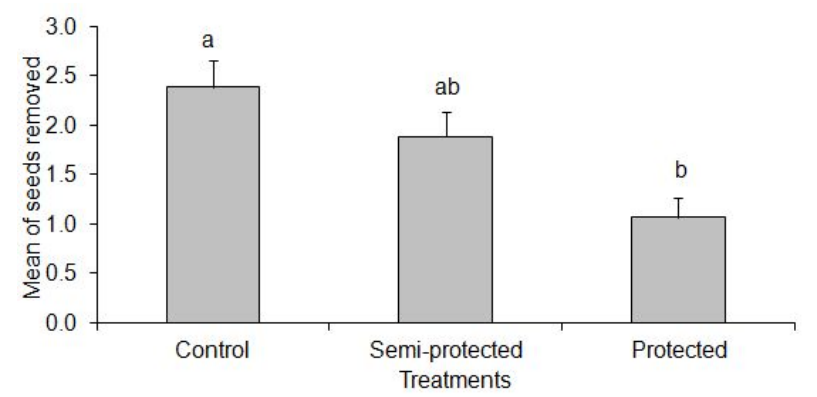

Figure 4. Mean of seeds removed among treatments in the area with predominance of jackfruit trees. The bars indicate the means and standard deviation of seeds removed. Different letters represent a significant difference

Of the 17 photographic records obtained in both study areas, two were records of Didelphis aurita (11.7\%), five of Nasua nasua (29.4\%), five of Trinomys paratus (29.4\%) three of Dasypus novemcinctus (14.3\%) and one each of Dasiprocta leporina (5.9\%) and Hidrochaeris hydrochaeris (5.9\%). Of these species only $T$. paratus and D. leporina feed on medium and large seeds and photographic records of $T$. paratus with seeds in its mouth (Figure 5) confirm that this species could be a potential seed disperser of $A$. heterophyllus.

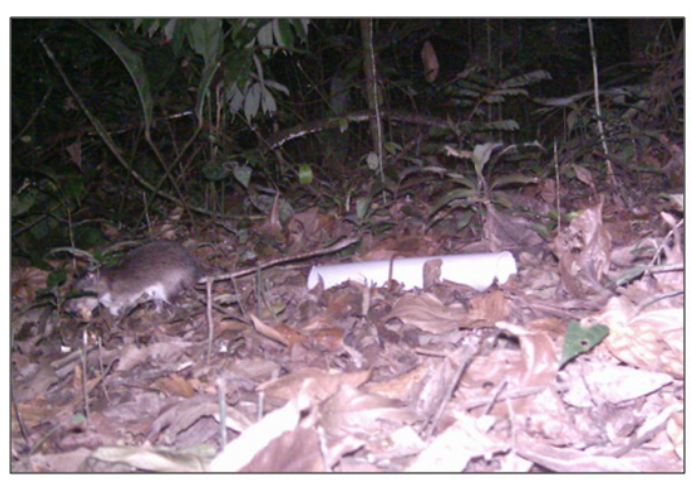

Figure 5. Photographic record of $T$. paratus with seeds of $A$. heterophyllus of the experiment in its mouth

\section{Discussion}

In general, the highest rates of re moval of $A$. heterophyllus seeds occurred in areas with a predominance of jackfruit trees, especially in the semi-protected treatment, which only allowed small species of mammals to access the seeds. Areas with high density or provision of resources are easily found by animals, which makes the use of these areas by individuals different from the consumption of other species with a more uneven distribution and with a lower supply of 
resources[22]. Based on this, the area with a predominance of jackfruit trees in REBIO presents a wide supply of resources, which promotes greater removal rate of seeds by individuals.

Studies in forests have assigned high seed removal rates to small mammals[23-27], which are also important seed dispersers [28, 29]. Small rodents are mostly considered seed predators [30] and may limit population growth of certain plants if the amount of seeds that are dispersed is insufficient or if the quality of the dispersal is inadequate[31]. Seed predation by small rodents is an important factor of seed mortality in the Neotropics[32]. However, it can contribute to the increase in the establishment of seedlings for germination in other potential sites away from the mother plant[33-35].

The absence of a significant difference between the control and semi-protected treatments in the jackfruit area indicates that small mammals, especially $T$. paratus, may have been the main dispersers of A. heterophyllus seeds in the area. These results are reinforced by the photographic records, since $T$. paratus was the species most often recorded by the camera traps (more than $40 \%$ of the records). Reference[36] found that on islands of Panama the other species of spiny rats (genus Proechimys) buried seeds of the palm tree Astrocaryum standleyanum, acting as effective secondary seed dispersers[37]. Similar to verified in this study, the rodent Oryzomys oniscus was the most responsible for seed predation in northeastern Brazil[38], and like $T$. paratus may operate as an effective large-seed predator/disperser in forest.

Conversely, significantly higher removal rates in the control treatments when compared with the protected and semi-protected treatments in native forest areas, point to the fact that medium and large mammals are also important groups in the removal of seeds in native areas of the REBIO. Similar results were found by Reference[39] at the Caetetus Ecological Station (SP), where the seeds in the open (control) treatment were removed three times more than in treatments that only small mammals and invertebrates could access. Reference[14] found that unprotected seeds in the Los Tuxt las Biological Station (Mexico) experienced a dramatic risk of predation, with levels ranging from 50 to $80 \%$. In according to reference[40] rodent species may be operating as active seed predators in frag ments of Atlantic forest.

The various photographic records of specimens of $T$. paratus with $A$. heterophyllus seeds in its mouth suggest that this species acts as a disperser, since it takes the seeds away from the adult plant and probably buries them as do the other spiny rats of the genus Proechimys[36]. According to Reference[9] and[41] small rodents of the genus Trinomys spp. consume fruits and seeds of many Atlantic Forest species, being considered good seed dispersers since they take them far a way from the adult plant. Thus, it seems that $T$. paratus is the main disperser of $A$. heterophyllus removing most of the seeds and contributing decisively to the expansion of jackfruit trees at the Duas Bocas Biological Reserve.
Data from the camera traps reinforce the hypothesis that small mammals are removing most of the seeds of $A$. heterophyllus. Among the species considered potential seed dispersers recorded by camera traps is Dasyprocta agouti that consumes / disperses seeds of the Acuri (Attalea phalerata). Agoutis (genus Dasyprocta) display a behavior in which they bury few seeds in different locations. This strategy would be more efficient for dispersal, because animals cannot return to all the sites where they have stored seeds, increasing the chance of recruitment[42].

According to Reference[16], while exotic species are rare in undisturbed tropical forests, many species can become invasive and even cause drastic changes to the ecosystem, facilitating their o wn dominance over native species. Similar to that seen in this study at the Duas Bocas Biological Reserve, the invasion and prevalence of extensive areas of jackfruit (A. heterophyllus) was also observed in the Parque Nacional da Tijuca in Rio de Janeiro[16].

When direct effects caused by the invasive species are not noticed, the population control is not usually considered an alternative. In this way, g radually as the jackfru it populations colonize the environment and slow growth typical of native tree species [43], the effects caused by these plants in the ecosystem may go unnoticed for a long time. However, for the Duas Bocas Biological Reserve these effects are noticeable[20] and management programs for this species should be planned and implemented.

Issues related to species conservation through management strategies are often more complex than the simple remediation of the primary cause[44]. Interventions should take into account the new ecological interactions that have developed and how the removal of the species would affect the local physical environ ment[16]. Thus, the removal of this exotic jackfruit species (A. heterophyllus) in the Duas Bocas Biological Reserve should be performed, however, the results of this study point to some facts that should be taken into account. The additional supply of jackfruit fruits and seeds allows many species of mammals to increase their populations in this area. This is easily verified by the high abundance of T. paratus rodents in these areas [45], the large number of photographic records obtained of various species of mammals and the frequent encounters with species of medium mammals (Cebus nigritus, Callithrix geoffroyi and Nasua nasua) consuming fru its of this species (unpublished data). Thus, management should be carried out partially, gradually and slowly, so that the populations of vertebrate species that now depend on this resource for food do not suffer a drastic impact.

\section{Conclusions}

The results of this study showed that there was a higher seed removal in the semi-protected treatment in the area with jackfruit trees than in native forest, and in native forest the removal was higher in the control than in the other treatments. This demonstrated that medium and large mammals are 
important groups in the removal of seeds in native areas and that small rodents was in jackfruit area. The species of spiny-rat Trinomys paratus was a potential seed disperser of Artocarpus heterophyllus in Duas Bocas Biological Reserve. The management of the area should be carried out partially, gradually and slowly, so that the populations of vertebrate species that now depend on this resource for food do not suffer a drastic impact.

\section{ACKNOWLEDGEMENTS}

We thank the Graduate Program in Ecosystem Ecology of the University Vila Velha (UVV). We also thank the State Environmental Institute (IEMA) for the collection permit and the Environmental Manager Fabiano Z. Novelli, and staff of the Duas Bocas Biological Reserve.

\section{REFERENCES}

[1] Schupp, E.W. Seed and early seedling predation in the forest understory and in treefall gaps. Oikos, vol.51, pp.71-78, 1988.

[2] Wang, B.C., T.B. Smith. Closing the seed dispersal loop. Trends in Ecology and Evolution, vol.17, pp.379-385, 2002.

[3] Clutton-Brock, T.H., P.H. Harvey. Mammals, resources and reproductive strategies. Nature, vol.273, pp.191-195, 1978.

[4] Cerqueira, R. Fatores ambientais e a reprodução de marsupiais e roedores no leste do Brasil. Arquivos do Museu Nacional do Rio de Janeiro, vol.63, no.1, pp.29-39, 2005.

[5] Fleming, T.H. Patterns of tropical vertebrate frugivore diversity. Annual Review of Ecology and Systematics vol.18, pp.91-109, 1987.

[6] DeMattia, E.A., L.M. Curran, B.I. Rathcke. Effects of small rodents and large mammals on neotropical seeds. Ecology, vol.85, no.8, pp.2161-217,. 2004.

[7] Pimentel, D.S., M. Tabarelli. Seed dispersal of the palm Attalea oleifera in a remnant of the Brazilian Atlantic Forest. Biotropica, vol.36, pp.74-84, 2004.

[8] Fleury, M., M. Galetti. Forest fragment size and microhabitat effects on palm seed predation. Biological Conservation, vol.131, pp.1-1,. 2006.

[9] Galetti, M., C.I. Donatti, A.S. Pires, P.R. Guimarães, P. Jordano. Seed survival and dispersal of an endemic Atlantic Forest palm: the combined effects of defaunation and Forest fragmentation. Botanical Journal of the Linnean Society, vol.151, pp.141-149, 2006.

[10] Lopez, L., J. Terborgh. Seed predation and seedling herbivory as factors in tree recruitment failure on predator-free forested islands. Journal of Tropical Ecology, vol.23, pp.129-137, 2007.

[11] Guimarães, P.R., P.F.M. Lopes, M.L. Lyra, A.P. Muriel. Fleshy pulp enhances the location of Syagrus romanzoffiana (Arecaceae) fruits by seed-dispersing rodents in an Atlantic forest in south-eastern Brazil. Journal of Tropical Ecology, vol. 21, pp.109-112, 2005.

[12] Briani, D.C., E.M. Vieira, M.V. Vieira. Nests and nesting sites of Brazilian forest rodents (Nectomys squamipes and Oryzomys intermedius) as rev ealed by a spool-and-line device. Acta Theriologica, vol.46, pp.331-334, 2001.

[13] Talamoni, S.A., M.M. Dias. Population and community ecology of small mammals in southeastern Brazil. Mammalia., vol.63, pp.167-181, 1999.

[14] Dirzo, R., E. Mendoza, P. Ortíz. Size-Related Differential Seed Predation in a Heavily Defaunated Neotropical Rain Forest. Biotropica, vol.39, pp.355-362, 2007.

[15] Cunha, A.A., M.V. Vieira, C.E.V. Grelle Preliminary observations on habitat, support use and diet in two non-native primates in an urban Atlantic forest fragment: The capuchin monkey (Cebus sp.) and the common marmoset (Callithrixjacchus) in the Tijuca forest, Rio de Jan eiro. Urban Ecosystems, vol. 9, pp.351-359, 2006.

[16] Abreu, R.C.R., P.J.F.P. Rodrigues. Exotic tree Artocarpus heterophyllus (Moraceae) invades the Brazilian Atlantic Rainforest. Rodriguésia, vol.61, pp.677-688, 2010.

[17] Perdomo, M. L.M.S. Magalhães. Ação alelopática da jaqueira (Artocarpus heterophyllus) em laboratório. Floresta e Ambiente, vol.14, pp.52-55, 2007.

[18] Ab'Saber, A.N. Os domínios morfoclimáticos da América do Sul. Primeira aproximação. Geomorfologia, vol.52, pp.1-21, 1977.

[19] Köppen, W. Climatología: con un estudio de los climas de la tierra. Fondo de Cultura Económica, México, pp.479, 1948.

[20] Boni, R., F.Z. Novelli, A.G. Silva. Um alerta para os riscos de bioinvasão de jaqueiras, Artocarpus heterophyllus Lam. na Reserva Biológica Paulo Fraga Rodrigues, antiga Reserva Bioló gica Duas Bocas, no Espírito Santo, Sudeste do Brasil. Natureza on line, vol.7, pp.51-55. 2009.

[21] Zar, J.H. Biostatistical Analysis. Prentice-Hall Press, New Jersey, pp.663, 2008.

[22] Vieira, E.M., P. Izar. Interactions between aroids and arboreal mammals in the Brazilian Atlantic rainforest. Plant Ecology, vol.145, pp.75-82, 1999.

[23] Asquith, N.M., S.J. Wright, M.J. Clauss, Does mammal community composition control recruitment in the neotropical forests? Evidence from Panama. Ecology, vol.78, pp.941-946, 1997.

[24] Iob, G., E.M. Vieira. Seed predation of Araucaria angustifolia (Araucariacae) in the Brazilian Araucaria Forest: influence of deposition site and comparative role of small and 'large' mammals. Plant Ecology, vol.198, pp.185-198, 2008.

[25] Brum, F.T., L.S. Duarte, S.M. Hartz. Seed removal patterns by vertebrates in different successional stages of Araucaria forest advancing over southern Brazilian grasslands. Community Ecology, vol.11, pp.35-40, 2010.

[26] Chauvet, S., P. Forget. Edge effects on post-dispersal seed removal in a fragmented rain forest in French Guiana. J. Trop. Ecol., vol.21, pp.113-116, 2005.

[27] Sánchez-Cordero, V., R. Martínez-Gallardo. Postdispersal fruit and seed removal by forest-dwelling rodents in a lowland 
rainforest in Mexico. J. Trop. Ecol., vol.14, pp.139-151, 1998.

[28] Horn, G.B., A. Kindel, S.M. Hartz. Akodon montensis (Thomas 1913) (Muridae) as a disperser of endozoochoric seeds in a coastal swamp forest of southern Brazil. Mamm. Biol.,vol.74, pp.325-329, 2008.

[29] Williams, P.A., B.J. Karl, P. Bannister, W.G. Lee. Small mammals as potential seed dispersers in New Zealand. Austral Ecol., vol.25, pp.523-532, 2000.

[30] Janzen, D.H. Seed predation by animals. Annu. Rev. Ecol. Syst. vol.2, pp.465-492, 1971.

[31] Schupp, E.W. Quantity, quality and the effectiveness of seed dispersal by animals. Vegetation, vol.108, pp.15-29, 1993.

[32] Grenha, V., M.V. Macedo, A.S. Pires, R.F. Monteiro. The role of Cerradomys Subflavus (Rodentia, Cricetidae) as seed predator and disperser of the Palm Allagoptera Arenaria. Mastozoología Neotropical, vol.17, pp.61-68, 2010.

[33] Forget, P.M. Post-dispersal predation and scatterhoarding of Dipteryx panamensis (Papilionaceae) seeds by rodents in Panama. Oecologia, vol.94, pp.255-261, 1993.

[34] Longland, W.S., S.H. Jenkins, S.B. Van Der Wall, J.A. Veech, S. Pyare. Seedling recruitment in Oryzopsis hymenoides: are desert granivores mutualists or predators? Ecology, vol.82, pp.3131-3148, 2001.

[35] Fenner, M., K. Thompson. The Ecology of seeds. University Press, Cambridge, pp.260, 2005.

[36] Hoch, G.A., G.H. Adler. Removal of black palm (Astrocaryum standleyanum) seeds by spiny rats (Proechimys semispinosus). Journal of Tropical Ecology, vol.13, pp.51-58, 1997.

[37] Wright, S.J. The myriad consequences of hunting for vertebrates and plants in tropical forests. Smithsonian Tropical Research Institute, Balboa, Ancón, Republic of Panama, vol.6, pp.73-86, 2003.

[38] Pinto, S.R., A.M.M. Santos, M. Tabarelli. Seed predation by rodents and safe sites for large-seeded trees in a fragment of the Brazilian Atlantic forest. Brazilian Journal of Biology, vol.69, pp.763-771, 2009.

[39] Christianini, A.V., M. Galetti. Spatial variation in post-dispersal seed removal in an Atlantic Forest: Effects of habitat, location and guilds of seed predators. Acta Oecologica, vol.32, pp.328-336, 2007.

[40] Pimentel, D.S., M. Tabarelli. Seed dispersal of the palm Attalea oleifera in a remnant of the Brazilian Atlantic forest. Biotropica, vol.36, pp.74-84, 2004

[41] Vieira, E.M., M.A. Pizo, P. Izar. Fruit and seed exploitation by small rodents of the Brazilian Atlantic Forest. Mammalia, vol.4, pp.533-539, 2003.

[42] Vander Wall, S.B. The evolutionary ecology of nut dispersal. Botanical Review, vol.67, pp.74-117, 2001.

[43] Silvertown, J., M. Franco, I. Pisanty, A. Mendoza. Comparative plant demography - relative importance of life-cicle components to the finite rate of increase in woody and herbaceous perennials. Journal of Ecology, vol.81, pp.465-476, 1993.

[44] Courchamp, F., R. Woodroffe, G. Roemer. Removing Protected Populations to Save Endangered Species. Science, vol.302, pp.1532, 2003.

[45] Pinto, M.M. Remoção de sementes de Artocarpus heterophyllus LAM. (Moraceae) em área de floresta nativa e área com dominância de Jaqueira na Reserva Biológica de Duas Bocas, Cariacica, ES. Dissertation. Universidade Vila Velha, 2011 